\title{
Lectin Binding as a Probe of Proliferative and Differentiative Phases in Primary Monolayer Cultures of Cutaneous Keratinocytes ${ }^{1}$
}

\author{
WARREN W. KU and ISADORE A. BERNSTEIN ${ }^{2}$ \\ Departments of Environmental and Industrial Health, and of Biological Chemistry, \\ The University of Michigan, Ann Arbor, Michigan 48109-2029
}

\begin{abstract}
The surface of cells in the cutaneous epidermis of the newborn rat exhibits a discrete change in lectin-binding specificity from Griffonia simplicifolia I-B4 (GS I-B4), specific for $\alpha$-D-galactosyl residues, to Ulex europeus agglutinin I (UEA), specific for $\alpha$-L-fucose, as the cell leaves the basal layer and differentiates. Primary monolayer cultures of rat keratinocytes maintained in low $\mathrm{Ca}^{2+}$ medium $(0.08 \mathrm{~m} M)$ exhibited a characteristic unimodal pattern in the ratio of bound UEA to bound GS I-B4 (UEA/B4 ratio) over a 7-day culture period as determined by a quantitative fluorometric assay. The UEA/B4 ratio was initially low between Days 1 and $2(0.56 \pm 0.05)$, steadily increased to a maximum of $0.84 \pm 0.09$ between Days 2 and 4 , and then gradually decreased to $0.41 \pm 0.07$ between Days 6 and 7. Estimation of DNA synthesis showed (a) a higher $\left[{ }^{3} \mathrm{H}\right]$ thymidine incorporation when the UEA/B4 ratio was low and (b) a steady but lower incorporation between Days 3 and 4 , coincident with the higher UEA/B4 ratio. Autoradiographic results further showed that cells stained intensely with UEA failed to incorporate $\left[{ }^{3} \mathrm{H}\right]$ thymidine into their nuclei. Electrophoresis of $\left[{ }^{3} \mathrm{H}\right]$ fucose-labeled material isolated on UEA-Sepharose $4 \mathrm{~B}$ revealed that the changes in labeling by $\left[{ }^{3} \mathrm{H}\right]$ fucose, bound UEA, and the UEA/B4 ratio in the monolayer were related in part to variable expression of "96K-associated UEA-bound" radioactivity corresponding to a major class of lectin-specific cell-surface glycoproteins (GP96 fraction) identified in situ. Overall, the results suggest that (a) the increase in the UEA/B4 ratio between Days 2 and 4 reflects the progression of a proportion of the cells in the monolayer to an early spinous cell stage, the ultimate fate of which is desquamation into the medium and (b) the decrease in the UEA/B4 ratio between Days 5 and 7 reflects a consequent proliferative response to this loss of cells. This system should be useful for studying environmental influences on the homeostasis of cell proliferation and differentiation in the cutaneous epidermis. (c) 1988 Academic Press, Inc.
\end{abstract}

The skin comes in contact with many toxic agents. It is well established that a host of chemical and physical factors affects the normal homeostasis of proliferation and differentiation in the mammalian cutaneous epidermis [1-19]. The response of the epidernis to must environmental stimuli is controlled by a negative feedback loop which assures, under normal circumstances, that cells lost through desquamation are replaced by cell proliferation [20]. An environmentally induced disruption in the balance between proliferation and differentiation in the lowermost epidermal cell layers would ultimately lead to alterations in the outermost

1 This investigation was supported in part by Grant 5 RO1 AM 15206 from the National Institutes of Health, US Public Health Service, Department of Health and Human Services and by the United States Army Medical Research and Development command, contract DAMD 17-82-C-2198. The views, opinions or findings contained in this report are those of the authors and should not be construed as position, policy, or decision of the agency supporting this research.

${ }^{2}$ To whom reprint requests should be addressed. 
layers. In the area of cutaneous toxicology, investigation of the effects of environmental influences on epidermal cell homeostasis would be greatly facilitated by the availability of reliable probes to identify changes in the proliferating and differentiating cell compartments.

Lectins are carbohydrate-binding proteins or glycoproteins of nonimmune origin which, when fluorescently labeled, have been used to reveal cell-surface carbohydrate changes during epidermal differentiation [21-27]. The surface of cells in the newborn rat epidermis exhibits a discrete change in lectin-binding specificity as the cell leaves the basal layer and differentiates [26]. The isolectin, Griffonia simplicifolia I-B4 (GS I-B4), specific for $\alpha$-D-galactosyl residues ( $\alpha$-D$\mathrm{Gal}$ ), shows preferential binding to basal cell surfaces. Ulex europeus agglutinin I (UEA), specific for $\alpha$-L-fucose ( $\alpha$-L-Fuc), preferentially binds to the surfaces of spinous and lower granular cells, and is therefore considered a marker of keratinocyte differentiation. Furthermore, cells in the layer immediately above the basal layer (suprabasal/early spinous) exhibit surface binding of both UEA and GS I-B4 [28].

The biochemical nature of the material exhibiting UEA and GS I-B4 binding has been studied $[29,30]$. Both lectins bind to a major class of cell-surface glycoproteins of an apparent molecular weight of 96K (GP96 fraction) which possess similar charge properties and are similar in the nature of their carbohydrate moieties [30]. The results of studies using intact newborn rat skin have also shown a steady increase in the ratio of UEA-bound to GS I-B4-bound GP96 fraction as the material came from isolated cell preparations containing a progressively higher proportion of differentiated cells [31]. These results are consistent with the findings in situ in which UEA binding increases and GS I-B4 binding decreases with epidermal differentiation. This GP96 fraction appears to be a useful marker for monitoring the normal progression of the pathway of differentiation and keratinization in newborn rat epidermis.

On the basis of the above evidence and of studies utilizing glycosidases [31], it has been proposed that the change from GS I-B4 to UEA binding specificity is a result of the addition of $\alpha$-L-Fuc to block the binding activity of nonreducing terminal $\alpha$-D-Gal residues on the GS I-B4-binding cell-surface GP96 form. Data suggest that the necessary transferase for this conversion is present in the newborn rat epidermis [32]. Furthermore, some of the GP96 material exhibits both lectin binding characteristics and may consist of intermediates in the conversion from GS I-B4 to UEA binding specificity [30].

In vitro, submerged primary cultures of rat keratinocytes maintained in low $\mathrm{Ca}^{2+}$ medium $(0.08-0.11 \mathrm{mM})$ grow as a monolayer, proliferate rapidly, and exhibit morphological similarities to epidermal basal cells in situ. Recent evidence indicates that these monolayer cultures exhibit both UEA and GS I-B4 binding when dual fluorescent probes are employed [28]. These findings suggest that, although maintenance of keratinocytes in low $\mathrm{Ca}^{2+}$ medium inhibits stratification and terminal differentiation, it does not inhibit the early stages of differentiation [28].

As part of ongoing research to develop a keratinocyte culture system to study 
environmentally induced changes, we assessed the utility of lectin binding to the cell surface as a probe of keratinocyte proliferation and differentiation in monolayer cultures of rat keratinocytes. Specifically, studies were designed (a) to characterize the expression of UEA and GS I-B4 binding over time in monolayer cultures of rat keratinocytes and (b) to determine if the ratio of bound UEA to bound GS I-B4 (UEA/B4 ratio) is an indicator of proliferative and early differentiative phases, presumably to an early spinous or a spinous cell stage. It was postulated that the UEA/B4 ratio would be a representation of the relative size of the proliferating and differentiating cell compartments in the monolayer cultures. It was predicted that a high UEA/B4 ratio would reflect a greater proportion of cells in the monolayer at some early stage of differentiation. A low ratio would reflect a higher fraction of proliferating (basal) cells in the monolayer. Since cell proliferation and the commitment to differentiation are not static processes, the UEA/B4 ratio was determined over time to assess whether the monolayer cultures exhibit a characteristic and reproducible pattern related to duration in culture with respect to this parameter. Consequently, an environmentally induced disruption in this characteristic pattern could then be determined.

In this paper, we report that primary monolayer cultures of rat keratinocytes exhibit a characteristic pattern in the UEA/B4 ratio over a 7-day period that is consistent with (a) the progression of a proportion of the monolayer to an early spinous cell stage and (b) a subsequent proliferative response by the monolayer to the loss of differentiated cells through desquamation. This system should be useful for studying environmental influences on the homeostasis of cell proliferation and differentiation in the cutaneous epidermis.

\section{MATERIALS AND METHODS}

\section{Cell Culture}

Keratinocytes were isolated from newborn rats obtained from a randomly inbred colony of CFN albino rats maintained in this laboratory. Dorsal skin removed from 1- to 2-day-old newborn rats was treated with $0.25 \%$ crude trypsin (Difco Laboratories, Detroit, MI) for $10-12 \mathrm{~h}$ at $4^{\circ} \mathrm{C}$. The epidermis was separated from the dermis, cells were brushed from the dermal side, and keratinocytes were separated on an isotonic $38 \%$ Percoll density gradient [P. Ribeiro, personal communication]. Cells isolated from the lowermost Percoll band $(\varrho>1.075 \mathrm{~g} / \mathrm{cc})$ were suspended to a final density of $1.6 \times 10^{6}$ cells $/ \mathrm{ml}$ in low $\mathrm{Ca}^{2+}$ medium. This medium consisted of calcium-free Eagle's minimum essential medium (MEM) supplemented with $10 \%$ Chelex-treated fetal calf serum [33], $10 \mu \mathrm{g} / \mathrm{ml}$ insulin, 10 $\mu \mathrm{g} / \mathrm{ml}$ hydrocortisone, $100 \mathrm{IU} / \mathrm{ml}$ penicillin, $100 \mu \mathrm{g} / \mathrm{ml}$ streptomycin, $0.5 \mu \mathrm{g} / \mathrm{ml}$ fungizone, and was adjusted to $0.08-0.11 \mathrm{mM} \mathrm{Ca}{ }^{2+}$ by the addition of calcium chloride. The cells were seeded in NUNC $16-\mathrm{mm} 4$-well multidishes at $4-5 \times 10^{5}$ cells $/ \mathrm{cm}^{2}$. Cultures were maintained in low $\mathrm{Ca}^{2+}$ medium at $35^{\circ} \mathrm{C}$ in a humidified $5 \% \mathrm{CO}_{2}$ : air environment. The medium was changed every other day. Confluency was routinely achieved 2 days postseeding.

\section{Quantitative Fluorometric Lectin-Binding Assay of Monolayers}

The ratio of bound UEA to bound GS I-B4 (UEA/B4 ratio) was determined by a modification of the method of Monsigny et al. [34]. The modification permits the simultaneous determination of the quantity of UEA and GS I-B4 bound to the same monolayer by monitoring two separate fluorescent analogs spectrofluorometrically. Monolayer cultures were first cooled on ice for $5 \mathrm{~min}$. The entire assay was carried out on ice in order to minimize internalization of bound lectin. Cultures were then rinsed with ice-cold phosphate-buffered saline (PBS), $\mathrm{pH} 7.2$, with $0.1 \mathrm{mMCaCl}$ and $0.1 \mathrm{mM} \mathrm{MgCl}$, and incubated for $10 \mathrm{~min}$ in $1 \%$ bovine serum albumin (BSA) in PBS to reduce nonspecific binding of 
lectins. Then, fluorescein (FITC)-labeled GS I-B4 (Sigma Chemical Co.. St. Louis, MO) and rhodamine-labeled UEA (Vector Laboratories, Burlingame, CA), each at a final concentration of $25 \mu \mathrm{g} / \mathrm{ml}$ in BSA/PBS, were added. Sample blanks received BSA/PBS. After incubation for $2 \mathrm{~h}$ to achieve saturation in binding, cultures were rinsed with PBS and specifically bound lectin was extracted by incubation for $1 \mathrm{~h}$ in $100 \mathrm{mM}$ methyl- $\alpha$-D-galactopyranoside (Me- $\alpha$-D-Gal) and $100 \mathrm{mM} \alpha$-L-fucose ( $\alpha$ L-Fuc) in PBS. It has been previously determined that greater than $90 \%$ of bound GS I-B4 and bound UEA is extracted from the monolayer under these conditions. The UEA/B4 ratio was determined spectrofluorometrically with a Perkin Elmer Model 650-40 fluorescence spectrophotometer. FITClabeled GS I-B4 was excited at $496 \mathrm{~nm}$ and the emission was detected at $520 \mathrm{~nm}$. Rhodamine-labeled UEA was excited at $556 \mathrm{~nm}$ and the emission was detected at $580 \mathrm{~nm}$. All measurements were carried out at room temperature. The absolute quantities (in micrograms) of lectin bound were calculated based on comparison to a FITC-labeled GS I-B4/rhodamine-labeled UEA standard and the UEA/B4 ratio was then determined.

\section{Lectin Staining and Fluorescent Microscopy}

Monolayer cultures. Monolayer cultures were grown on 12-mm round glass coverslides (Arthur $\mathrm{H}$. Thomas C., Philadelphia, PA) inserted into the wells of $16-\mathrm{mm}$ 4-well multidishes. The monolayers grown on glass coverslides exhibited morphological characteristics similar to those grown on plastic. For lectin staining, the monolayers were rinsed with PBS at room temperature. Then, FITC-labeled GS I-B4 and rhodamine-labeled UEA, each at a final concentration of $25 \mu \mathrm{g} / \mathrm{ml}$ in PBS, were added. After incubation for $45 \mathrm{~min}$ at room temperature, the monolayers were rinsed with PBS, fixed with $5 \%$ neutral buffered formalin, and mounted in a modified polyvinyl alcohol medium on standard microscope slides.

Detached rounded cells. Detached floating cells from the medium of monolayer cultures maintained in low $\mathrm{Ca}^{2+}$ medium for 6 days were concentrated on standard microscope slides by centrifugation in IEC Cytobuckets (International Equipment Company, Needham Heights, MA) at $200 \mathrm{~g}$ for $10 \mathrm{~min}$. The cells attached to the slides were allowed to air dry for 15-20 min at room temperature. After rinsing the cells with PBS, the slides were flooded with the fluorescent-labeled lectins. After incubation at room temperature for $45 \mathrm{~min}$, the cells were rinsed with PBS and mounted in polyvinyl alcohol medium.

In all cases, the specificity of binding of the fluorescent-labeled lectins was verified by incubating monolayer cultures or detached rounded cells on slides in the presence of the respective inhibitory monosaccharides at a concentration of $50 \mathrm{mM}$ : Me- $\alpha$-D-Gal for GS I-B4 and $\alpha$-L-Fuc for UEA.

Microscopy. The lectin-stained cultures and slides were examined with a Zeiss photomicroscope III using transmitted light and equipped with a $490-\mathrm{nm}$ excitation filter and a $530-\mathrm{nm}$ barrier filter for FITC-labeled GS I-B4, and a 546-nm excitation filter and 590-nm barrier filter for rhodamine-labeled UEA. Monolayers processed for both autoradiography and staining with FITC-labeled UEA were examined with a Nikon DIAPHOT-TMD inverted microscope equipped with an epifluorescence attachment and Nikon FE2 camera.

\section{Estimation of DNA Synthesis}

Incorporation of $\left[{ }^{3} H\right]$ thymidine into DNA. Monolayer cultures were pulse labeled with [methyl$\left.{ }^{3} \mathrm{H}\right]$ thymidine $\left({ }^{3} \mathrm{H}\right] \mathrm{TdR}$ ) (New England Nuclear (NEN), Boston, MA) $\left(0.5 \mu \mathrm{Ci} / \mathrm{ml}\right.$ ) for $3 \mathrm{~h}$ at $35^{\circ} \mathrm{C}$. Cultures were then cooled on ice and the UEA/B4 ratio was determined as described. The monolayers were precipitated with ice-cold trichloroacetic acid (TCA) and further processed for the determination of DNA and acid-precipitable radioactivity by a modification of the method described by Setaro and Morley [35]. $\mathrm{NaOH}(0.1 \mathrm{~N})$ rather than $\mathrm{KOH}(1.0 \mathrm{~N})$ was used to dissolve the TCA precipitate [36]. DNA was determined spectrophotofluorometrically as described by Setaro and Morley [35]. To determine monolayer incorporation of acid-precipitable radioactivity, samples were diluted in ACS (aqueous counting scintillant) (Amersham, Arlington Heights, IL) and counted in a Packard Tricarb liquid scintillation spectrometer. Incorporation was normalized to that of DNA and expressed as $\mathrm{cpm} / \mu \mathrm{g}$ DNA.

Autoradiography. Monolayer cultures growing at $35^{\circ} \mathrm{C}$ were pulse labeled with $\left[{ }^{3} \mathrm{H}\right] \mathrm{TdR}(2 \mu \mathrm{Ci} / \mathrm{ml})$ for $2 \mathrm{~h}$ at intervals of approximately one-half days (10-12 h) to 7 days. After washing in PBS, the monolayers were fixed with $10 \%$ neutral buffered formalin, washed in deionized water, and air dried. Cell wells were coated with Kodak NTB-2 emulsion. dried, and developed in D-19 after 5 days of exposure at $0-4^{\circ} \mathrm{C}$. The number of cells possessing only darkly labeled nuclei were counted per $1000-2000$ cells in the monolayer. The relationship between UEA staining and the incorporation of 
$\left.{ }^{3} \mathrm{H}\right] \mathrm{TdR}$ into DNA as revealed by autoradiography was determined. Monolayer cultures grown on $12-$ $\mathrm{mm}$ coverslides were pulse labeled with $\left[^{3} \mathrm{H}\right] \mathrm{TdR}(1.0 \mu \mathrm{Ci} / \mathrm{ml} \times 30 \mathrm{~min})$, stained with FITC-UEA, fixed, and then processed for autoradiography. The presence of the Kodak NTB-2 emulsion and the developing procedure did not interfere with the observation of FITC fluorescence.

\section{Estimation of the Kinetics of Cell Production}

Monolayer cell counts were carried out using a hemocytometer after disaggregation with $0.05 \%$ crude trypsin/0.02\% EDTA and light scraping with a rubber policeman. Cell counts were carried out daily to Day 7 in culture.

\section{$\left[{ }^{3} H\right]$ Fucose Labeling and Lectin-Affinity Chromatography}

Monolayer cultures were incubated at $35^{\circ} \mathrm{C}$ with $20 \mu \mathrm{Ci} / \mathrm{ml}\left[5,6-{ }^{3} \mathrm{H}\right] \mathrm{L}-$ fucose (ICN Radiochemicals, Irvine, $\mathrm{CA}$ ) at intervals from $24 \mathrm{~h}$ to 7 days. After incubation, the cultures were cooled on ice, rinsed with ice-cold PBS containing $2 \mathrm{~m} M$ phenylmethylsulfonyl fluoride (PMSF), and solubilized in $0.5 \%$ (v/v) Nonidet-P40 (NP-40)/PBS for $4 \mathrm{~h}$ at $0-4^{\circ} \mathrm{C}$. The NP-40-solubilized material was dialyzed extensively against PBS, the radioactivity was determined, and then the material was subjected to affinity chromatography on columns of UEA and GS I-B4-Sepharose 4B. The incorporation of $\left[{ }^{3} \mathrm{H}\right]$ fucose into NP-40-soluble material was normalized to that of protein as determined by Lowry et al. [37] and expressed as $\mathrm{cpm} / \mu \mathrm{g}$ protein.

Affinity columns were prepared by couplng the UEA and GS I-B4 lectins to CNBr-activated Sepharose 4B [38]. The $\left[{ }^{3} \mathrm{H}\right]$ fucose-labeled NP-40-solubilized material was passed through the UEASepharose 4B column and rinsed with at least 5 column vol of NP-40/PBS to remove material binding nonspecifically. Specifically bound material was eluted with $10 \mathrm{mg} / \mathrm{ml}(60 \mathrm{mM}) \alpha$-L-Fuc. In a separate experiment, this UEA-bound $\left[{ }^{3} \mathrm{H}\right]$ fucose-labeled material was applied to a column of GS I-B4-Sepharose 4B, rinsed, and eluted with $10 \mathrm{mg} / \mathrm{ml}(40 \mathrm{mM}) \mathrm{Me}-\alpha-\mathrm{D}-\mathrm{Gal}$. In all cases, an equal amount of total protein was applied to the lectin columns for each time point. The recovery of sample material from both columns was $90-100 \%$. The $\left[{ }^{3} \mathrm{H}\right]$ fucose-labeled material isolated from the UEA-Sepharose $4 \mathrm{~B}$ column was subjected to SDS-polyacrylamide gel electrophoresis.

\section{SDS-Polyacrylamide Gel Electrophoresis (SDS-PAGE) and \\ Radioactivity Determination}

SDS-PAGE of $\left[{ }^{3} \mathrm{H}\right]$ fucose-labeled UEA-bound material was performed according to the system by Laemmli [39]. The UEA-bound fractions were dialyzed extensively against deionized water and lyophilized. Samples were prepared for SDS-PAGE by boiling for $5 \mathrm{~min}$ in $2 \%(\mathrm{w} / \mathrm{v}) \mathrm{SDS}, 10 \%(\mathrm{w} / \mathrm{v})$ glycerol, $0.2 \%(\mathrm{w} / \mathrm{v})$ dithiothreitol, and $0.004 \%(\mathrm{w} / \mathrm{v})$ bromphenol blue. Electrophoresis was carried out on a vertical $8 \%$ polyacrylamide resolving gel with a $3 \%$ stacking gel. An equivalent amount of protein for each time point was applied to gel lanes. Radioactivity was analyzed by incubating gel slices ( $2 \mathrm{~mm}$ ) in NCS tissue solubilizer (Amersham, Arlington Heights, IL) overnight and counting in a Packard Tricarb liquid scintillation spectrometer. The following standards were used for calibration of molecular weights: phosphorylase $b(92.5 \mathrm{~K})$, albumin $(66.2 \mathrm{~K})$, ovalbumin $(45 \mathrm{~K})$, and carbonic anhydrase (31K) (Bio-Rad Laboratories, Richmond, CA).

\section{RESULTS}

\section{UEA/B4 Ratio in Monolayer Cultures}

Selected phase-contrast photomicrographs taken over a culture period of 7 days revealed no significant morphological differences in the monolayer cultures maintained in low $\mathrm{Ca}^{2+}$ medium (Fig. 1). Differential lectin staining of these monolayer cultures with FITC-labeled GS I-B4 and rhodamine-labeled UEA at Day 2, Day 4, and Day 6 showed that the cells bound both lectins as reported by Brown and Bernstein [28] (Fig. 2). Although the monolayer cultures appeared to exhibit some qualitative differences in both the intensity and the selectivity of staining over time in culture, an objective interpretation or quantitative estimate 

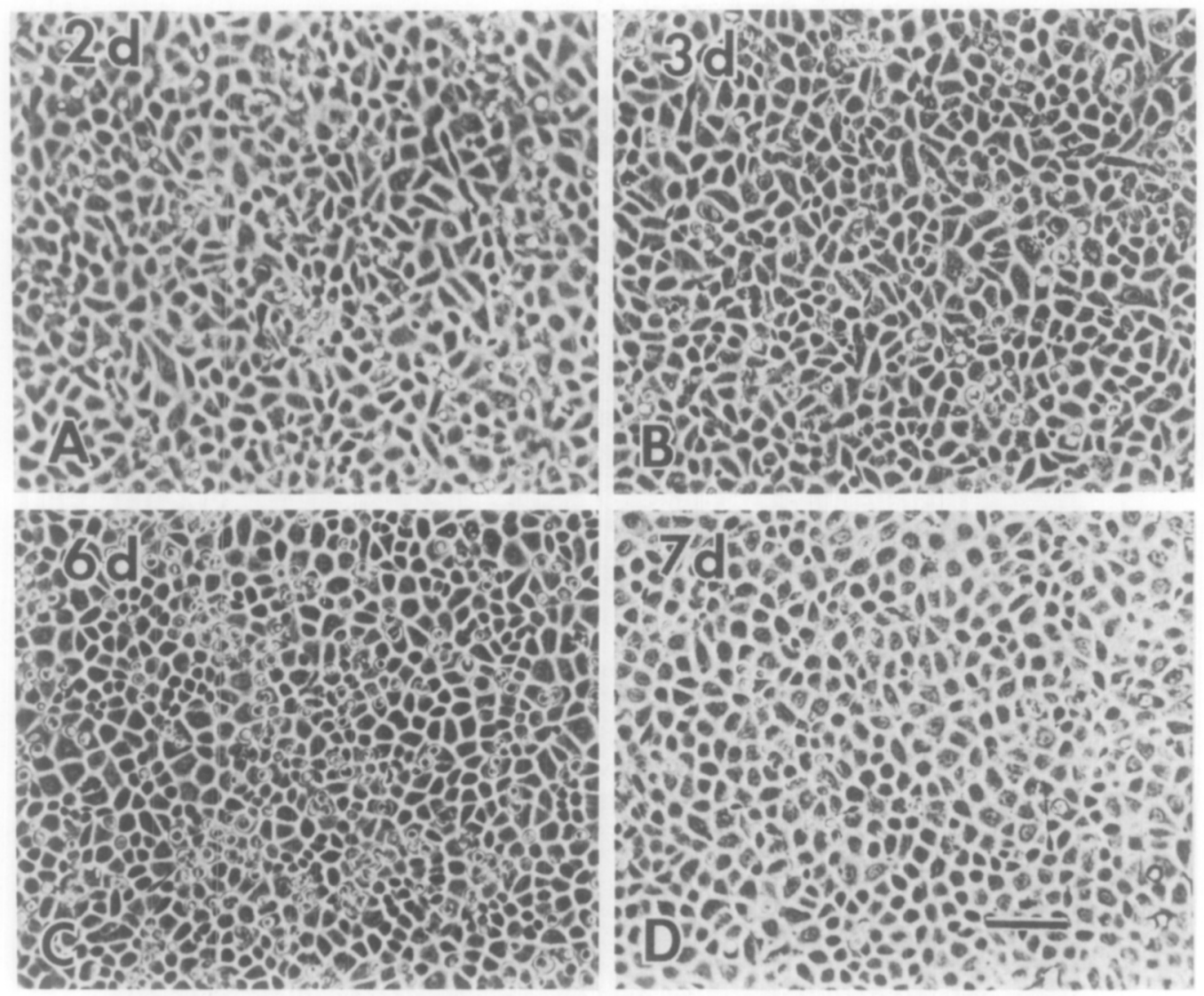

Fig. 1. Phase-contrast photomicrographs of monolayer cultures of rat keratinocytes maintained in low $\mathrm{Ca}^{2+}$ medium. $(A, B, C, D) 2,3,6$, and 7 days in culture, respectively. Bar $=100 \mu \mathrm{m}$.

was rather difficult. Therefore, the UEA/B4 ratio in the monolayer cultures was determined by a modified quantitative fluorometric lectin-binding assay [34]. It was postulated that the UEA/B4 ratio would be a reflection of the degree of an early stage of keratinocyte differentiation occurring in culture. The results showed that the monolayer cultures exhibited a characteristic unimodal pattern in the UEA/B4 ratio over a culture period of 7 days (Fig. 3). The UEA/B4 ratio was initially low between Days 1 and $2(0.56 \pm 0.05)$, steadily increased to a maximum of $0.84 \pm 0.09$ between Days 2 and 4 , and then gradually decreased to $0.41 \pm 0.07$ between Days 6 and 7. The UEA/B4 ratios determined at shorter time intervals (10-12 h) within the 7-day culture period confirmed the shape of the ratio curve depicted in Fig. 3 (data not shown).

The absolute quantities of bound UEA and bound GS I-B4 in the monolayer cultures are depicted in Fig. 4. The results showed that the amount of bound UEA exhibited a pattern similar to that of the UEA/B4 ratio over the culture period of 7 days. The initial rise in the UEA/B4 ratio (Day 2-Day 4) was a result of a greater relative increase in UEA binding than in GS I-B4 binding. The decay 
$\mathrm{CS} \mathrm{I-B}$
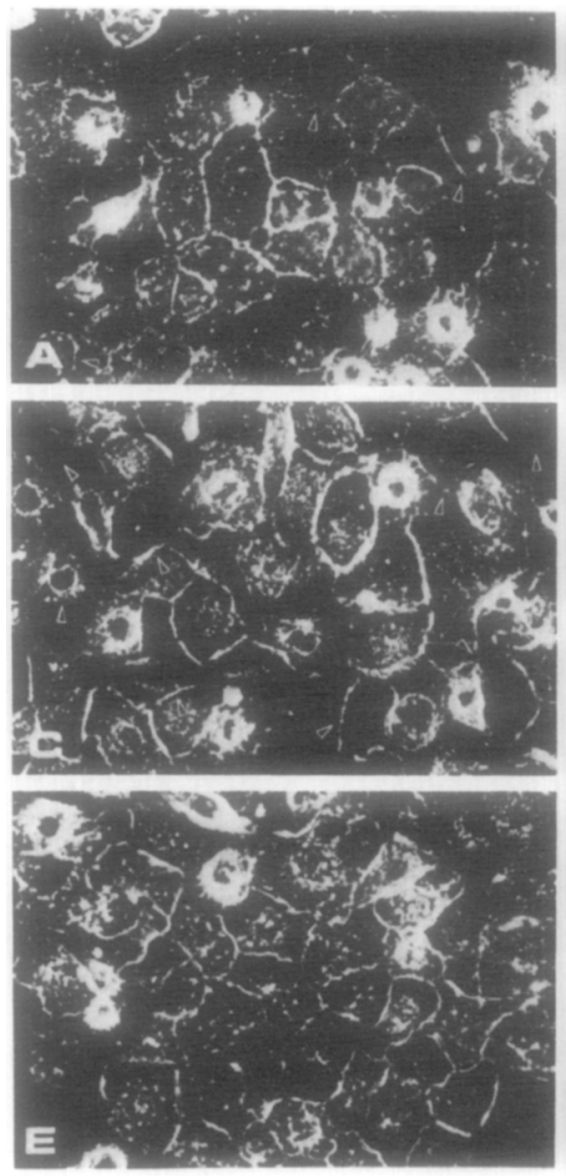

\section{UEA}
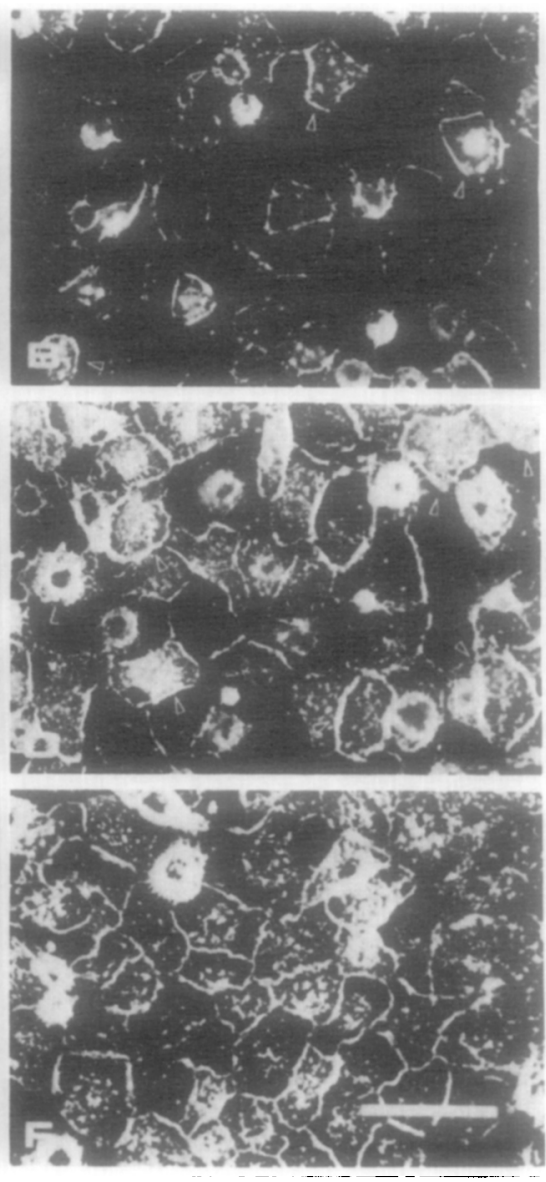

Fig. 2. Lectin staining of monolayer cultures of rat keratinocytes maintained in low $\mathrm{Ca}^{2+}$ medium with FITC-labeled GS I-B4 and rhodamine-labeled UEA. $(A, C, E)$ Monolayer cultures stained with FITC-labeled GS I-B4 at 2, 4, and 6 days in culture, respectively. $(B, D, F)$ Same fields as $(A, C, E)$ stained with rhodamine-labeled UEA. Note the presence of cells in the monolayers intensely stained by rhodamine-labeled UEA which appeared dark upon examination for FITC-labeled GS I-B4 (arrowheads). Bar $=100 \mu \mathrm{m}$.

in the UEA/B4 ratio (Day 5-Day 7) was attributed to both an increase in GS I-B4 binding and a decrease in UEA binding during this time period. This period was also associated with the presence of a great number of large rounded cells floating in the medium (Fig. $5 a$ ). These detached cells were generally between 30 and 50 $\mu \mathrm{m}$ in diameter and possessed a high UEA/B4 ratio $(0.80-1.10)$. Furthermore, greater than $90 \%$ of these detached cells showed positive surface UEA staining and only faint GS I-B4 staining when examined fluoromicroscopically (Figs. $5 b$ and $5 c$ ). It was also determined that greater than $90 \%$ of these detached rounded cells failed to reattach on new substratum and form viable colonies. Overall, the results suggest that these large detached cells are predominantly early differenti- 


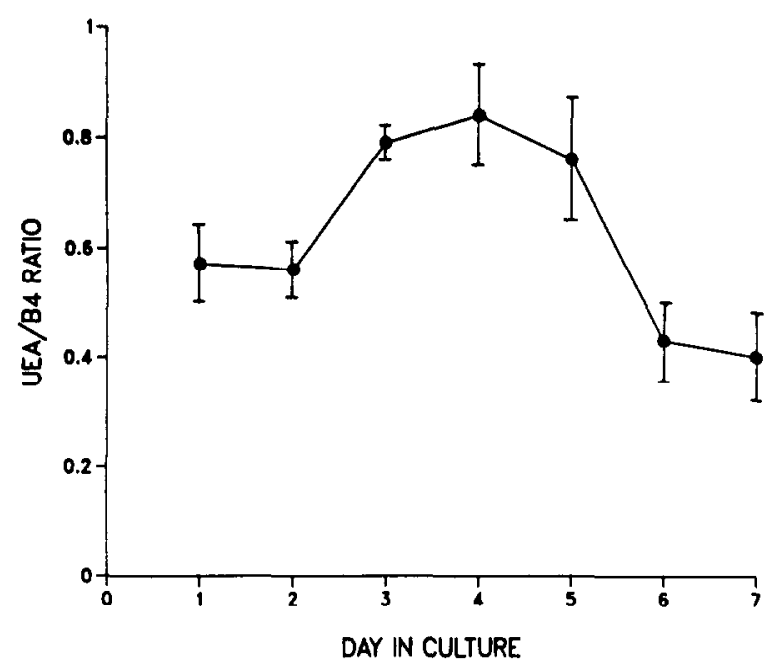

Fig. 3. UEA/B4 ratio over time in monolayer cultures of rat keratinocytes maintained in low $\mathrm{Ca}^{2+}$ medium. Cells were grown as a monolayer in low $\mathrm{Ca}^{2+}(0.08-0.11 \mathrm{mM})$ medium and the ratio of bound UEA to bound GS I-B4 in the same monolayer was determined spectrofluorometrically as described under Materials and Methods. The UEA/B4 ratio for each day in culture is expressed as the mean \pm standard deviation (SD) from seven separate experiments.
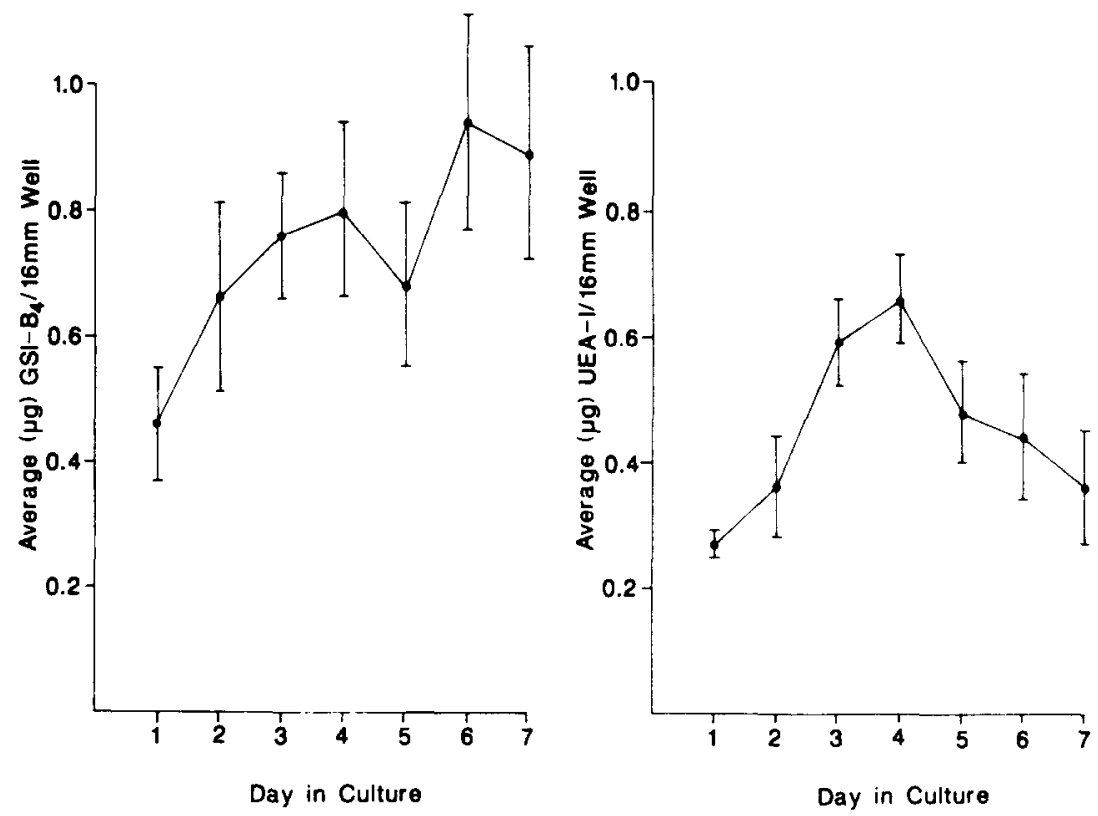

Fig. 4. Absolute quantities of bound GS I-B4 and bound UEA over time in monolayer cultures of rat keratinocytes maintained in low $\mathrm{Ca}^{2+}$ medium. The absolute quantities (in micrograms) of each lectin bound to the same monolayer were calculated based on the comparison to a FITC-labeled GS IB4/rhodamine-labeled UEA standard and expressed as microgram lectin bound/16-mm well. The results are expressed as the mean \pm SD from seven separate experiments. 

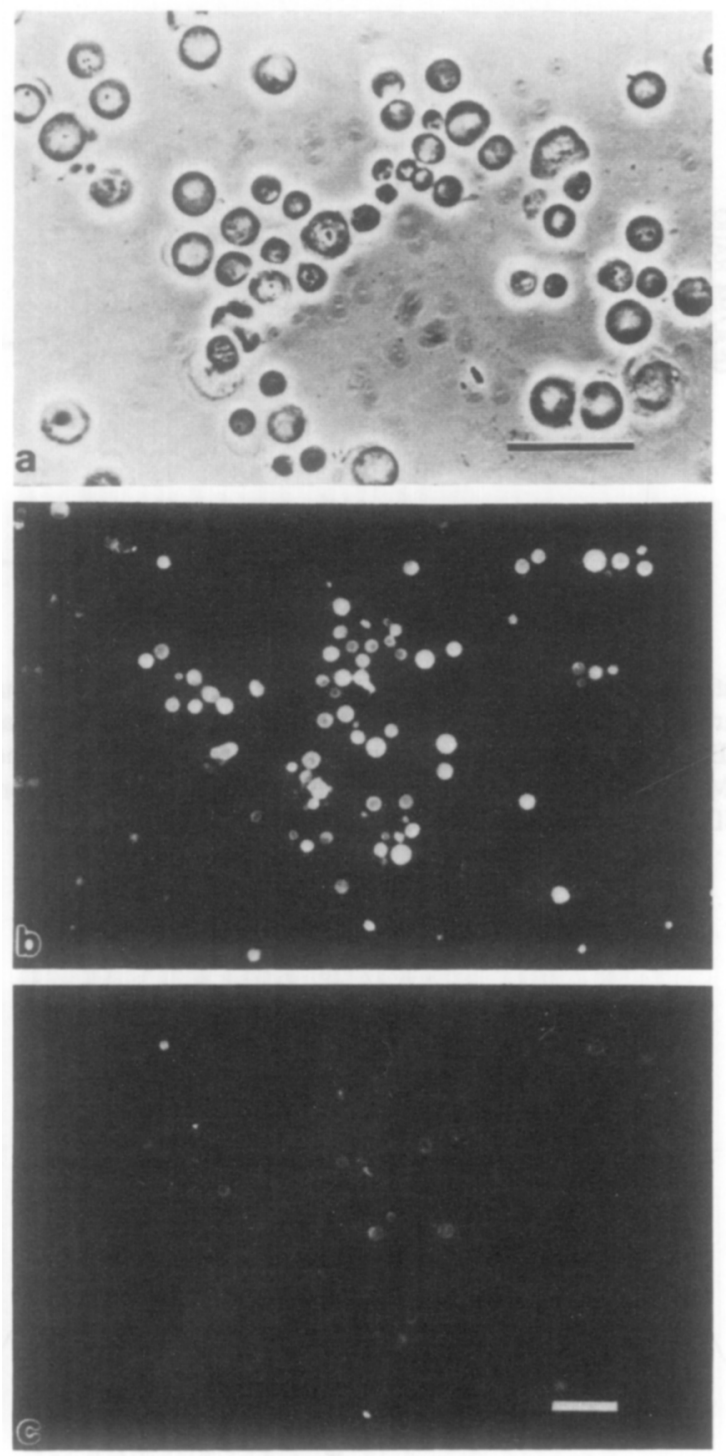

Fig. 5. Nature of detached rounded cells floating in the low $\mathrm{Ca}^{2+}$ medium. The detached cells were generally between 30 and $50 \mu \mathrm{m}$ in diameter $(a)$, with the majority of the cells showing positive surface UEA staining $(b)$ and only faint GS I-B4 staining $(c)$. (b) Field of detached cells stained with rhodamine-labeled UEA. (c) Same field as (b) stained with FITC-labeled GS I-B4. Bar $(a, b, c)=100$ $\mu \mathrm{m}$.

ated cells (presumably at an early spinous or a spinous cell stage) lost from the monolayer through desquamation.

Estimation of DNA Synthesis and Cell Production in the Monolayer

Studies were undertaken to assess the relationship between the UEA/B4 ratio and replicative DNA synthesis in the monolayer cultures. Replicative DNA 


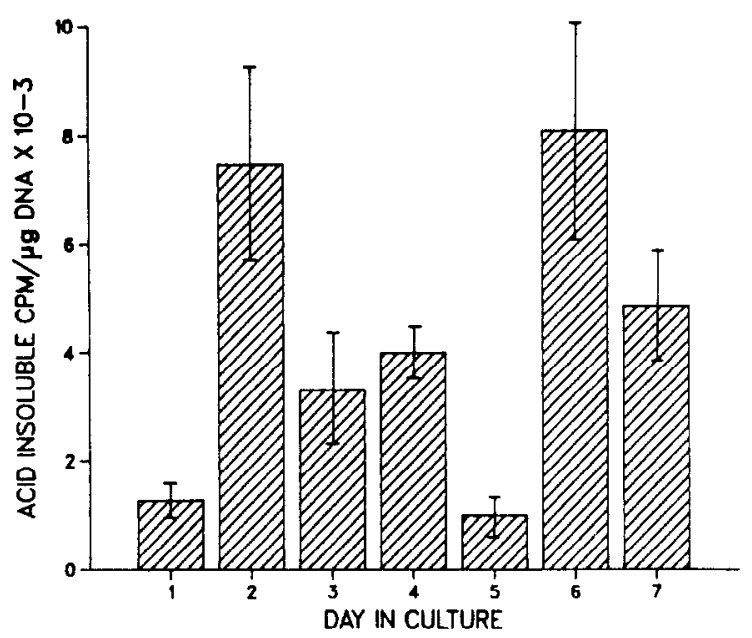

Fig. 6. Incorporation of $\left[{ }^{3} \mathrm{H}\right.$-]thymidine $\left(\left[{ }^{3} \mathrm{H}\right] \mathrm{TdR}\right)$ into acid-insoluble material over time in monolayer cultures of rat keratinocytes maintained in low $\mathrm{Ca}^{2+}$ medium. Monolayer cultures were pulse labeled with $\left[{ }^{3} \mathrm{H}\right] \mathrm{TdR}(0.5 \mu \mathrm{Ci} / \mathrm{ml} \times 3 \mathrm{~h})$ and incorporation of acid-insoluble (TCA-precipitable) radioactivity was determined and normalized to DNA. Results are expressed as the mean \pm SD from five separate experiments.

synthesis over the culture period of 7 days was estimated by the incorporation of $\left[{ }^{3} \mathrm{H}\right] \mathrm{TdR}$ into acid-precipitable material and by autoradiography.

Estimation of the incorporation of $\left[{ }^{3} \mathrm{H}\right] \mathrm{TdR}$ showed that the specific activity of DNA (cpm/ $\mu$ g DNA) was high when the UEA/B4 ratio was low, with the highest

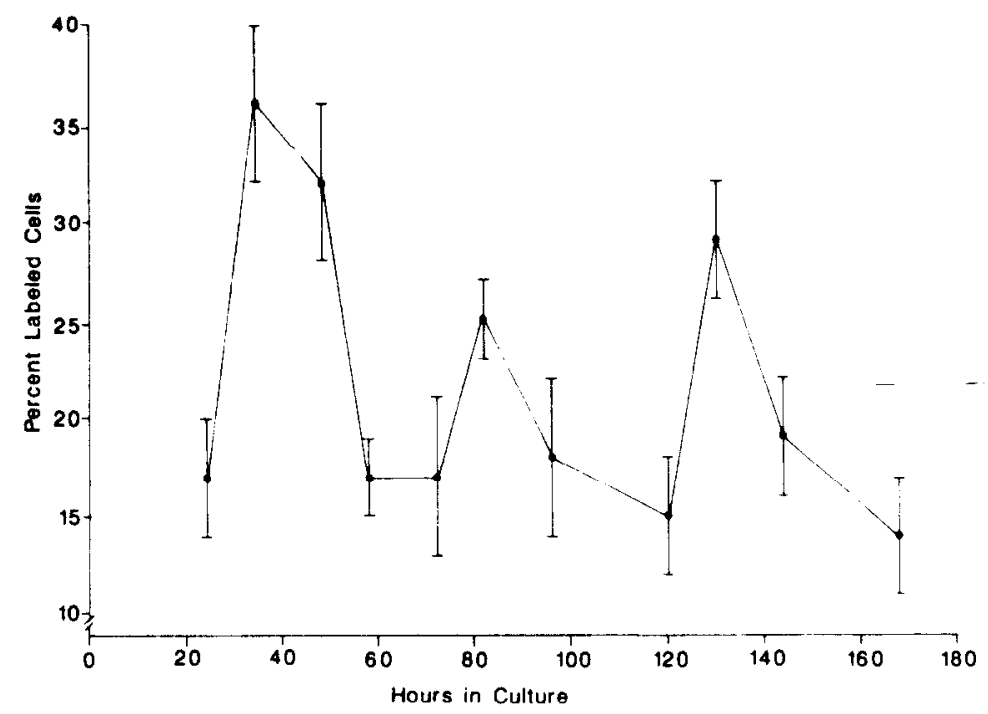

Fig. 7. Autoradiographic analysis of monolayer cultures of rat keratinocytes maintained in low $\mathrm{Ca}^{2+}$ medium. Monolayer cultures were pulse labeled with $\left.{ }^{3} \mathrm{H}\right] \mathrm{TdR}(2 \mu \mathrm{Ci} / \mathrm{ml})$ for $2 \mathrm{~h}$ at approximate one-half day (10-12 h) intervals to 7 days and processed for autoradiography as described under Materials and Methods. The number of cells possessing only darkly labeled nuclei were counted per $1000-2000$ cells in the culture. The results represent the mean \pm SD from three separate experiments. 
incorporation noted at Day 2 and Day 6 (Fig. 6). When the UEA/B4 ratio was approaching or at the maximum (Day 3-Day 5), there was a lower incorporation, with the lowest incorporation at Day 5.

Autoradiographic results of pulse-labeling experiments using $\left[{ }^{3} \mathrm{H}\right] \mathrm{TdR}$ were consistent with the $\left[{ }^{3} \mathrm{H}\right] \mathrm{TdR}$ incorporation data. There was a nearly synchronous pattern of DNA synthesis during the entire culture period, with peaks at or around 34-48 h (Day 1-Day 2), $82 \mathrm{~h}$ (Day 3-Day 4), and $130 \mathrm{~h}$ (Day 5-Day 6) (Fig. 7). A synchronous pattern of growth has also been reported by Elgjo et al. for primary cultures of newborn mouse epidermal cells [40].

Studies were carried out to determine the relationship between UEA staining and the incorporation of $\left[{ }^{3} \mathrm{H}\right] \mathrm{TdR}$ as revealed by autoradiography. Monolayer cultures grown on coverslides were labeled with $\left[{ }^{3} \mathrm{H}\right] \mathrm{TdR}$, stained with FITClabeled UEA, and processed for autoradiography. The results revealed that cells stained intensely with FITC-UEA failed to incorporate $\left[{ }^{3} \mathrm{H}\right] \mathrm{TdR}$ into their nuclei, whereas those cells exhibiting significant $\left[{ }^{3} \mathrm{H}\right] \mathrm{TdR}$ incorporation showed little or no staining (Fig. 8, arrowheads). Furthermore, the cells which were stained the most intense by FITC-UEA were the ones which had rounded-up or were about to detach from the monolayer surface.

The results from studies estimating the kinetics of cell production in the monolayer showed that, subsequent to the first major peak of replicative DNA synthesis at around $3448 \mathrm{~h}$, there was an almost $30 \%$ increase in monolayer cell number between Day 2 and Day 3 (Fig. 9). Furthermore, the decay noted in the UEA/B 4 ratio beginning at Day 4 was associated with a decrease of almost $40 \%$ in monolayer cell number between Day 4 and Day 5. As mentioned previously, this latter significant loss of cells is believed to be a result of the loss of early differentiated cells from the monolayer through desquamation. Subsequent to this loss of differentiated cells from the monolayer and to a third major peak of replicative DNA synthesis at $130 \mathrm{~h}$ was a $48 \%$ increase in monolayer cell number between Day 5 and Day 7. As mentioned previously, this period was also associated with a low UEA/B4 ratio.

\section{$\left[{ }^{3} H\right] T d R$ Fucose-Labeling Studies}

Monolayer cultures were labeled with $\left[{ }^{3} \mathrm{H}\right]$ fucose for $24-\mathrm{h}$ intervals between Day 2 and Day 7 and then solubilized with NP-40, a nonionic detergent. The profile of incorporation of $\left[{ }^{3} \mathrm{H}\right]$ fucose into NP-40-soluble material showed a pattern similar to the amount of bound UEA (Fig. 10) and the UEA/B4 ratio (Fig. 3). Affinity chromatography of $\left[{ }^{3} \mathrm{H}\right]$ fucose labeled NP-40-solubilized material from monolayers at Day 3-Day 4 (peak of labeling) on UEA-Sepharose 4B revealed that $60-70 \%$ of the radioactivity was bound to UEA. Results from the chromatography of this UEA-bound material on a GS I-B4-Sepharose 4B column showed that between 40 and $50 \%$ of this UEA-bound fraction was bound to GS I-B4. $\left[{ }^{3} \mathrm{H}\right]$ Fucose-labeled material extracted from the cells floating in the medium showed lectin binding characteristics similar to those of the material isolated from the monolayers. 

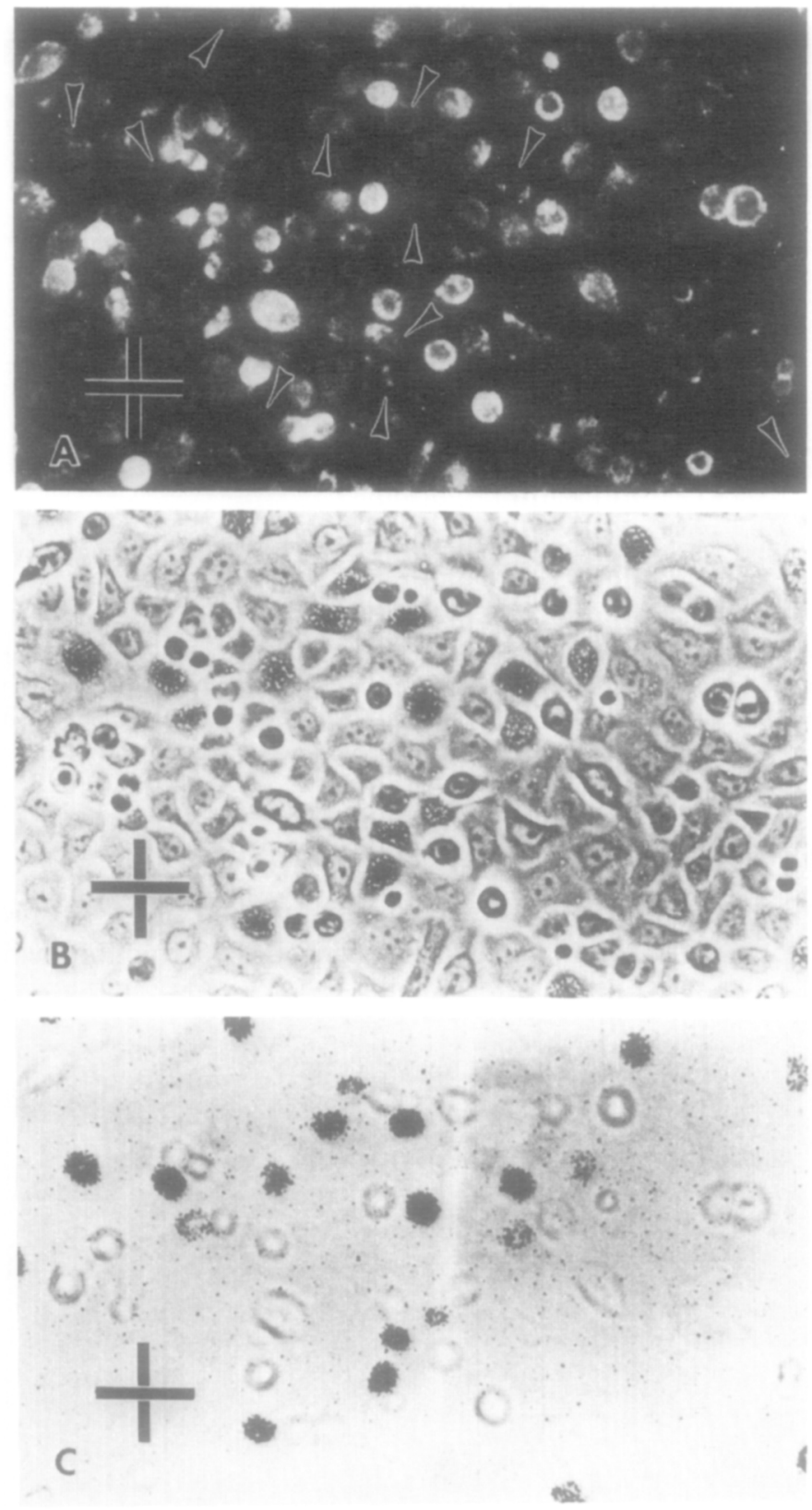

Fig. 8. The relationship between UEA staining and the incorporation of $\left[{ }^{3} \mathrm{H}\right]$ thymidine into DNA as revealed by autoradiography. Monolayer cuitures grown on coverslides $(12 \mathrm{~mm})$ were pulse labeled with $\left[{ }^{3} \mathrm{H}\right] \mathrm{TdR}(1.0 \mu \mathrm{Ci} / \mathrm{ml} \times 30 \mathrm{~min})$, stained with FITC-UEA, fixed, and then processed for autoradiography. $(A, B$ and $C$ ) Photomicrographs of the same field. The crosses in the three photomicrographs locate the same point in the field. $(A)$ With FITC filter; $(B)$ with phase objective, $40 \times$; $(C)$ minus phase ring to highlight labeled nuclei. The arrows in $(A)$ indicate the positions of cells labeled by $\left[{ }^{3} \mathrm{H}\right] \mathrm{TdR}$ as seen in the dark field. Magnification $250 \times$. 


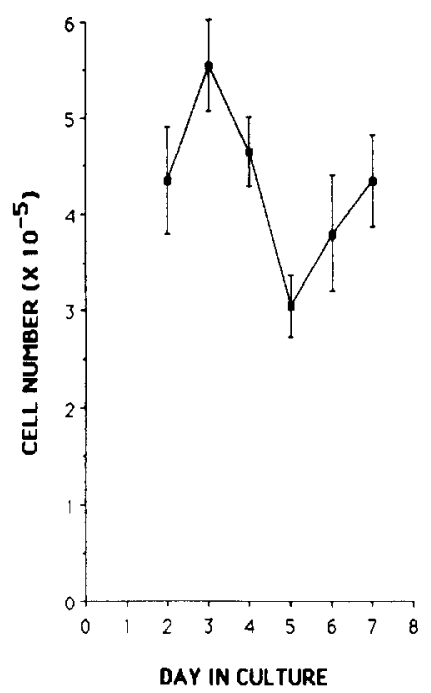

Fig. 9. Cell production over time in monolayer cultures of rat keratinocytes maintained in low $\mathrm{Ca}^{2+}$ medium. The cells from monolayer cultures were disaggregated and collected by treatment with $0.05 \%$ crude trypsin $/ 0.02 \%$ EDTA and light scraping. Cell number was determined using a hemocytometer.

\section{Gel Electrophoresis of $\left[{ }^{3} \mathrm{H}\right]$ Fucose-Labeled Material}

In situ, both UEA and GS I-B4 bind to a major class of cell-surface glycoproteins of an apparent molecular wcight of 96K (GP96 fraction) which possess similar charge properties and are similar in the nature of their carbohydrate

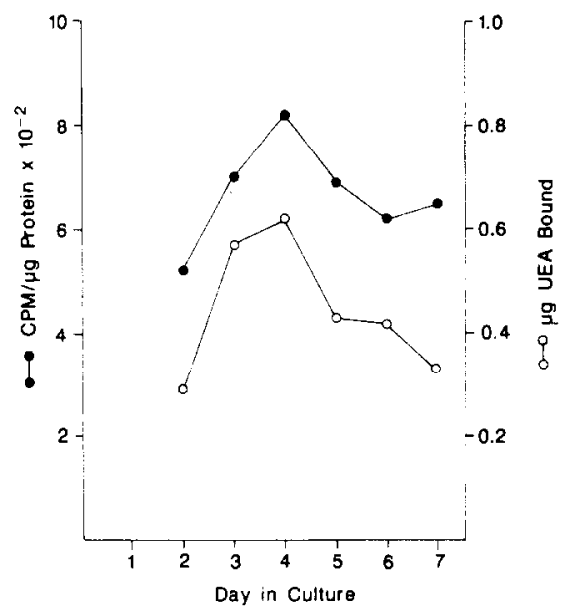

Fig. 10. Comparison of the amount of bound UEA $(O)$ and the incorporation of $\left[{ }^{3} \mathrm{H}\right]$ fucose into NP40 soluble material (O) over time in monolayer cultures of rat keratinocytes maintained in low $\mathrm{Ca}^{2+}$ medium. Monolayer cultures were labeled with $\left[{ }^{3} \mathrm{H}\right]$ fucose for $24-\mathrm{h}$ intervals between Day 2 and Day 7 and the amount of bound UEA was determined spectrofluorometrically. The incorporation of $\left[{ }^{3} \mathrm{H}\right] \mathrm{fu}-$ cose into NP-40-soluble material was determined and normalized to protein. 


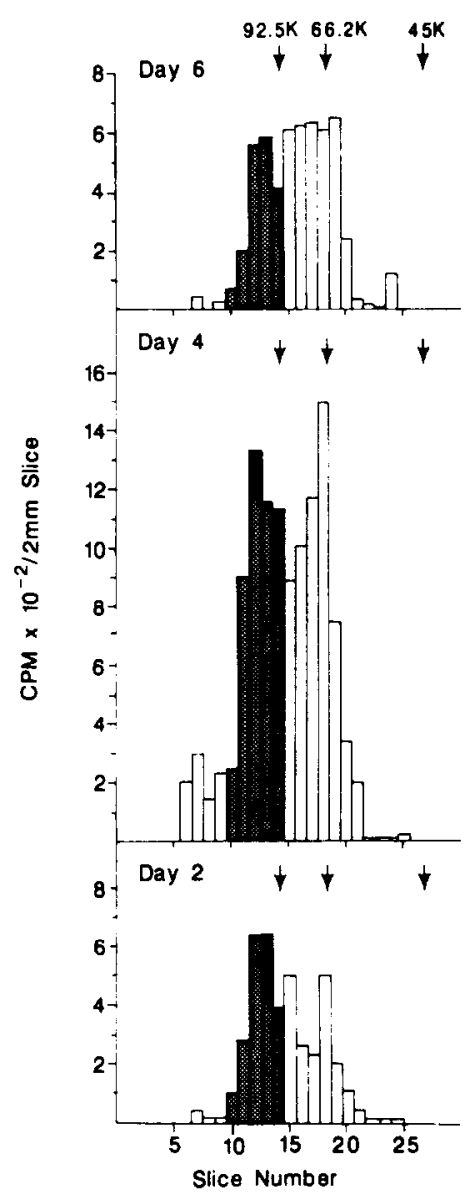

Fig. 11. Expression of 96K (GP96 fraction)-associated UEA-bound radioactivity at 2, 4, and 6 days in monolayer cultures of rat keratinocytes maintained in low $\mathrm{Ca}^{2+}$ medium. Monolayer cultures were labeled with $\left[{ }^{3} \mathrm{H}\right]$ fucose for 24-h intervals between Days 1 and 2, Days $3-4$, and Days $5-6$ and then solubilized with $0.5 \%$ NP- 40 . The UEA-bound $\left[{ }^{3} \mathrm{H}\right]$ fucose-labeled fractions were isolated by chromatography on UEA-Sepharose 4B and analyzed by SDS-PAGE as described under Materials and Methods. The shaded regions depict the amount of 96K-associated UEA-bound radioactivity expressed. This radioactivity generally represents between 30 and $50 \%$ of the total radioactivity in the resolving gel.

moieties [30]. This GP96 fraction can be revealed electrophoretically when either $\left[{ }^{3} \mathrm{H}\right]$ fucose or galactose oxidase $/ \mathrm{NaB}^{3} \mathrm{H}_{4}$ [41] is used to label the material [29].

Studies were carried out to determine the qualitative and quantitative nature of $\left[{ }^{3} \mathrm{H}\right]$ fucose-labeled UEA-bound components associated with the monolayer when the UEA/B4 ratio was low (Day 2 and Day 6) and when the ratio was at the maximum (Day 4). Monolayer cultures were labeled with $\left[{ }^{3} \mathrm{H}\right]$ fucose for $24-\mathrm{h}$ intervals between Days 1 and 2, Days 3-4, and Days 5-6, and then solubilized with NP-40. The UEA-bound $\left[{ }^{3} \mathrm{H}\right]$ fucose-labeled fractions were isolated by chromatography on UEA-Sepharose $4 B$ and were analyzed by SDS-PAGE.

SDS-PAGE analysis revealed a number of UEA-bound $\left[{ }^{3} \mathrm{H}\right]$ fucose-labeled components, with the majority of the radioactivity migrating between $60 \mathrm{~K}$ and 


\section{$312 \mathrm{Ku}$ and Bernstein}

100K (Fig. 11). The two major labeled components identified were at 96K (GP96 fraction) (shaded region) and about $77 \mathrm{~K}$. The radioactivity associated with the GP96 fraction generally represented $30-50 \%$ of the total radioactivity in the resolving gel. Previous studies have identified a number of other components in the UEA-bound fraction isolated in situ, including a band at $77 \mathrm{~K}[29,30]$. However, this $77 \mathrm{~K}$ component was exclusively a UEA-binding form and did not exhibit the dual lectin-binding properties of the GP96 fraction [29]. This $77 \mathrm{~K}$ component was not present in the gel radioactivity profile when the UEA-bound fraction was chromatographed on a column of GS I-B4-Sepharose 4B (data not shown). The results depicted in Fig. 11 also showed variable expression of both $96 \mathrm{~K}$ - and $77 \mathrm{~K}$-associated UEA-bound radioactivity at 2, 4, and 6 days. The amount of radioactivity associated with both the $96 \mathrm{~K}$ and $77 \mathrm{~K}$ band was higher at 4 days than at 2 and 6 days. Thus, there appeared to be different amounts of the UEA-bound GP96 present in the monolayer cultures for each time point that was consistent with the changes noted in the UEA/B4 ratio. The results suggest that the changes in $\left[{ }^{3} \mathrm{H}\right]$ fucose labeling in the monolayer, the amount of bound UEA, and the UEA/B4 ratio are related in part to the variable expression of "96Kassociated" UEA-bound radioactivity. This radioactivity corresponds to the major class of lectin-specific cell-surface glycoproteins (GP96 fraction) that is associated with the normal pathway of differentiation and keratinization in newborn rat epidermis in situ.

\section{DISCUSSION}

Previous studies by Hennings et al. [42] have shown that the pattern of growth and differentiation of mouse keratinocytes in culture is influenced by the level of calcium ion in the medium. Mouse keratinocytes maintained in medium containing $0.5-0.10 \mathrm{mM} \mathrm{Ca}{ }^{2+}$ grow as a monolayer and proliferate rapidly with a highgrowth fraction. The cells exhibit morphological similarities to basal epidermal cells in vivo [43]. Primary cultures of cutaneous keratinocytes from the newborn rat also grow as a monolayer in low $\mathrm{Ca}^{2+}$ medium and, like the mouse, can be induced to stratify and undergo terminal differentiation by raising the level of medium $\mathrm{Ca}^{2+}[44]$.

Although these monolayer cultures reveal no significant morphological differences over time in culture (Fig. 1), changes have been detected with respect to various biochemical or cytochemical markers of keratinocyte differentiation. Using lectins to probe the epidermal cell surface, studies by Brown and Bernstein [28] have shown that rat keratinocytes grown as a monolayer in low $\mathrm{Ca}^{2+}$ medium exhibit GS I-B4 binding, a property associated with the epidermal basal cell layer in situ [26]. However, a significant proportion of the monolayer also exhibited UEA binding, a property normally associated with differentiated keratinocytes. From these findings, it was suggested that some stage of keratinocyte differentiation that is independent of $\mathrm{Ca}^{2+}$-induced stratification is occurring in the monolayer cultures. This suggestion is supported by observations in human keratinocytes [45], in which a significant proportion of the cells in the low $\mathrm{Ca}^{2+}$ monolayer 
have been shown to contain involucrin, a precursor protein of the crosslinked envelope and a marker of terminal differentiation.

The results of the present study demonstrated that primary cultures of rat keratinocytes maintained in low $\mathrm{Ca}^{2+}$ medium exhibited a characteristic pattern in the UEA/B4 ratio over a period of 7 days (Fig. 3) that is consistent with distinct proliferative and early differentiative phases. Estimation of replicative DNA synthesis showed a relationship between the level of $\left[{ }^{3} \mathrm{H}\right] \mathrm{TdR}$ incorporation and the UEA/B4 ratio, with higher levels of incorporation noted when the UEA/B4 ratio was low and a steady but lower incorporation when the ratio was approaching or at the maximum (Fig. 6). In addition, the monolayer cultures showed a nearly synchronous pattern of DNA synthesis during the 7-day culture period as revealed by autoradiography (Fig. 7). The cells in the monolayer which showed the most intense staining with UEA failed to incorporate $\left[{ }^{3} \mathrm{H}\right] \mathrm{TdR}$ into their nuclei (Fig. 8) in contrast to those cells which showed little or no UEA staining. The results from studies of cell production in the monolayer showed that monolayer cell number increased subsequent to the major peaks of replicative DNA synthesis at $34-48 \mathrm{~h}$ and $130 \mathrm{~h}$ in culture (Fig. 9). Furthermore, a significant loss of cells from the monolayer between Day 4 and Day 5 was associated with a decay in the UEA/B4 ratio beginning at Day 4. This period was also associated with a decrease in the amount of bound UEA and with the presence of large round cells floating in the medium which showed predominantly positive UEAstaining of the surface. Subsequent to this significant loss of cells was an increase in the monolayer cell number, an increase in the amount of GS I-B4 bound, and a subsequent decrease in the UEA/B4 ratio.

The nature of the changes in the UEA/B4 ratio was revealed by labeling with $\left[{ }^{3} \mathrm{H}\right]$ fucose, lectin-affinity chromatography, and gel electrophoresis. The results demonstrated that the changes in the UEA/B4 ratio were related in part to variable expression of 96K-associated UEA-bound radioactivity, reflecting different amounts of the UEA-bound GP96 form present in the monolayer cultures during the culture period (Fig. 11). This corresponded to the major class of UEA and GS I-B4-binding cell-surface glycoproteins (GP96 fraction) identified in situ [32] that is associated with the normal pathway of epidermal differentiation and keratinization. Previous data from studies using cell preparations from intact newborn rat skin showed an increase in the ratio of UEA-bound to GS I-B4bound GP96 fraction as the ratio of spinous to basal cells increased in the harvested population of cells subjected to radiolabeling and fractionation [31]. The results in the present study suggested that a similar change occurs in the cells comprising the low $\mathrm{Ca}^{2+}$ monolayer.

Overall, the results suggest that (a) the increase in the UEA/B4 ratio between Day 2 and Day 4 reflects the progression of a proportion of the cells in the monolayer to an early spinous cell state, the ultimate fate of which is desquamation into the medium, and (b) the decrease in the UEA/B4 ratio between Day 5 and Day 7 reflects a proliferative response to differentiated cell loss through desquamation. Table 1 summarizes the chronology of events believed to be occurring in the monolayer cultures during the first 7 days of culture. 
TABLE 1

The chronology of events believed to be occurring in monolayer cultures of rat keratinocytes over a 7-day culture period

\begin{tabular}{ccc}
\hline $\begin{array}{c}\text { Day in } \\
\text { culture }\end{array}$ & Stage of monolayer & UEA/B4 ratio \\
\hline & & \\
1 & Proliferative & Low $(0.56 \pm 0.05)$ \\
2 & Differentiating/proliferating (reduced) & Increasing \\
3 & Early differentiative & Maximum $(0.84 \pm 0.09)$ \\
4 & Decreasing \\
5 & Desquamation (loss of differentiated cells) & Low $(0.41 \pm 0.07)$ \\
6 & Proliferative response to desquamation & \\
7 & & \\
\hline
\end{tabular}

The following model has been constructed based on the results of the present study.

Between Day 1 and Day 2 in culture, the monolayer is predominantly proliferative, serving to occupy culture surface during this initial period, with confluency routinely achieved by Day 2 in culture. The observed low UEA/B4 ratio and high specific activity of $\left[{ }^{3} \mathrm{H}\right] \mathrm{TdR}$ incorporation and $\left[{ }^{3} \mathrm{H}\right] \mathrm{TdR}$ labeling noted during this time period are consistent with such an interpretation.

Between Day 2 and Day 4, a period in which the monolayer has already reached confluency, a proportion of the cells in the monolayer cease DNA synthesis and progressively reach an early spinous or spinous cell stage. This interpretation is supported by the steady increase in the UEA/B4 ratio to a maximum at Day 4 (Fig. 3) and a steady but lower $\left[{ }^{3} \mathrm{H}\right] \mathrm{TdR}$ incorporation between Day 3 and Day 4 (Fig. 6) coincident with the higher UEA/B4 ratio. Two lines of experimental evidence suggested that the low $\mathrm{Ca}^{2+}$ monolayer cultures do not progress to the granular cell stage, a late differentiative stage. First, a monoclonal antibody raised against HRP-II (filaggrin), which stains only the granular layer and the lower stratum corneum in tissue sections of newborn rat skin using indirect immunofluorescence, does not stain the low $\mathrm{Ca}^{2+}$ monolayer [46]. Second, the activity of epidermal transglutaminase, a calcium-induced particulate enzyme which catalyzes cornified envelope formation [47], was low both in the low $\mathrm{Ca}^{2+}$ monolayer and in the cells detached into the medium compared to monolayer cultures switched from low to high calcium medium [49].

Between Day 4 and Day 6, there is continual desquamation of differentiated cells into the medium. A greater relative loss of absolute UEA binding compared to GS I-B4 binding was associated with this time period (Fig. 4). The results from cell production studies showed a $40 \%$ decrease in monolayer cell number during this time (Fig. 9). The cells shed into the medium are generally large and possess a high UEA/B4 ratio, with greater than $90 \%$ showing positive surface UEA binding and only faint GS I-B4 binding when examined fluoromicroscopically (Figs. $5 a-5 c$ ). It has also been determined that the majority $(>90 \%)$ of these shed cells fail to reattach on new substratum and form viable colonies. It is 
currently unknown what other markers of keratinocyte differentiation are coordinately expressed by the detached rounded cells. However, the activity of epidermal transglutaminase, localized in the upper malpighian and granular cell layer in situ [48], was low in low $\mathrm{Ca}^{2+}$ monolayer cultures compared to cultures switched to high $\mathrm{Ca}^{2+}$ medium, with no significant difference noted between the cells comprising the monolayer and those cells detached into the surrounding medium. It is interesting to note that in human keratinocytes maintained in low $\mathrm{Ca}^{2+}$ medium, positive staining with antiserum to involucrin is noted both in detached rounded cells as well as in keratinocytes occupying a suprabasal position in the monolayer [45].

A round of cell proliferation in response to loss of differentiated cells through desquamation occurs between Day 5 and Day 6 . This was supported by both (a) an increase in absolute GS I-B4 binding concomitant with a decrease in the UEA/B4 ratio and a high specific activity of $\left[{ }^{3} \mathrm{H}\right] \mathrm{TdR}$ incorporation and $\left[{ }^{3} \mathrm{H}\right] \mathrm{TdR}$ labeling and (b) a $48 \%$ increase in monolayer cell number during this time (Fig. 9).

The described keratinocyte culture system should be useful for studying environmental influences on the homeostasis of cell proliferation and differentiation in the mammalian cutaneous epidermis. The data suggest that differential lectin binding in monolayer cultures of rat keratinocytes may be useful as a probe of environmentally induced changes in (a) the progression of a proportion of the monolayer to an early spinous cell stage (UEA/B4 ratio between Days 2 and 4) and (b) the proliferative response to differentiated cell loss through desquamation (UEA/B4 ratio between Days 5 and 7). Such studies in keratinocyte culture would permit one to characterize environmentally induced changes in the absence of complicating factors encountered in vivo (i.e., dermal component, intact immune system). This would provide more controlled experiments and more reproducible data.

Specifically, in the area of cutaneous toxicology, the system may find utility as a screening assay for both environmental and industrial chemicals or potential topical therapeutic agents which induce changes in the cutaneous epidermis. Although the low $\mathrm{Ca}^{2+}$ keratinocyte culture system grows as a monolayer and does not stratify and undergo terminal differentiation [43], it appears to be a suitable model for studying environmentally induced changes in the lowermost nucleated epidermal cell layers (basal/early spinous) which may ultimately result in changes in the outermost layers.

The authors thank MIr. Robert Zidell for his technical assistance and advice in using the Nikon DIAPHOT Microscope System.

\section{REFERENCES}

1. Clausen, O. P. (1975) Virchows Arch. Cell. Pathol. 27, 205.

2. Slaga, T. J., Thompson, S., and Schuckler, E. A. (1974) Cancer Res. 34, 771.

3. Mirvish, S. S., Chu, C., and Clayson, D. B. (1978) Cancer Res. 38, 458.

4. Slaga, T. J., Borodon, G. T., and Boutwell, R. K. (1975) J. Natl. Cancer Inst. 55, 933.

5. Elgjo, K. (1968) Acta Pathol. Microbiol. Scand. 73, 316. 
6. Christophers, E., and Braun-Falco, O. (1970) J. Invest. Dermatol. 54, 437.

7. Osborne, R., and Greenlee, W. F. (1985) Toxicol. Appl. Pharmacol. 77, 434.

8. Gierthy, J. F., and Crane, D. (1984) Toxicol. Appl. Pharmacol. 74, 91.

9. Balmain, A., Alonso, A., and Fischer, J. (1977) Cancer Res. 37, 1538.

10. Yuspa, S. H., Ben, T., Patterson, E., Michaek, K., Elgjo, K., and Hennings, H. (1976) Cancer Res. 36, 4062.

11. Frei, J. V. (1977) J. Natl. Cancer Inst. 59, 299.

12. Argyris, T. S. (1980) Amer. J. Pathol. 98, 639.

13. Marks, F., Bertsch, S., and Furstenberger, G. (1979) Cancer Res, 39, 4183.

14. Yuspa, S. H., Ben, T., and Hennings, H. (1983) Carcinogenesis 1, 413.

15. Chopra, D. P., and Flaxman, B. A. (1975) J. Invest. Dermatol. 64, 19.

16. Marcelo, C. L., and Madison, K. C. (1984) Arch. Dermatol. Res. 263, 381.

17. Kubilus, J. (1983) J. Invest. Dermatol. 81 (suppl), $55 \mathrm{s.}$

18. Yuspa, S. H., Ben, T., and Steinert, P. (1982) J. Biol. Chem. 257, 9906.

19. Milstone, L. M., McGuire, J., and LaVigne, J. F. (1982) J. Invest. Dermatol. 79, 253.

20. Weiss, P. and Kavanau, J. L. (1957) J. Gen. Physiol. 41, 1-47.

21. Nieland, M. L. (1973) J. Invest. Dermatol. 60, 61.

22. Hashimoto, K., King, L. E., Yamanishi, Y., Beachey, E. H., and Maeyens, E. J. (1974) J. Invest. Dermatol. 62, 423.

23. Van Lis, J. M. J., and Kalsbeek, G. L. (1975) Brit. J. Dermatol. 92, 27.

24. Holt, P. J. A., Anglin, J. H., and Nordquist, R. E. (1979) Brit. J. Dermatol. 100, 237.

25. Nemanic, M. K., Whitehead, J. S. and Elias, P. M. (1983) J. Histochem. Cytochem. $31,887$.

26. Brabec, R. K., Peters, B. P., Bernstein, I. A., Gray, R. H., and Goldstein, I. J. (1980) Proc. Natl. Acad. Sci. USA 77, 477.

27. Reano, A., Faure, M., Jacques, Y., and Reichert, U. (1982) Brit. J. Dermatol. 107 (suppl. 23), 143.

28. Brown, R., and Bernstein, I. A. (1984) J. Cell Biol. 99, 314 a.

29. Zieske, J. D. (1981) Doctoral Thesis, The University of Michigan.

30. Ku, W. W., and Bernstein, I. A. (1985) Biochem. Biophys. Res. Commun. 132, 269.

31. Zieske, J. D., and Bernstein, I. A. (1982) J. Cell. Biol. 95, 626.

32. Zieske, J. D., and Bernstein, I. A. (1984) Biochem. Biophys. Res. Commun, 119, 1028.

33. Brennan, J. K., Mansky, J,, Roberts, G., and Lichtman, M. A. (1975) In vitro 11, 354.

34. Monsigny, M., Sene, C., and Obrenovitch, A. (1979) Eur. J. Biochem. 96, 295.

35. Setaro, F., and Morley, C. G. D. (1976) Anal. Biochem. 71, 313.

36. Abler, A. and Bernstein, I. A. Biochem. Biophys. Res. Commun, in press.

37. Lowry, O. H., Rosebrough, N. J., Farr, A. L., and Randall, R. J. (1951) J. Biol. Chem. $193,265$.

38. Blake, D. A., and Goldstein, I. J. (1980) Anal. Biochem. 102, 103.

39. Laemmli, U. K. (1970) Nature (London) 227, 680.

40. Elgjo, K., Hennings, H., Michael, D., and Yuspa, S. H. (1976) J. Invest. Dermatol. 66, 292.

41. Gahmberg, C. G., and Hakomori, S. I. (1973) J. Biol. Chem. 248, 4311.

42. Hennings, H., Michael, D., Cheng, C., Steinert, P., Holbrook, K., and Yuspa, S. H. (1980) Cell $19,245$.

43. Hennings, H., and Holbrook, K. A. (1983) Exp. Cell Res. 143, 127.

44. Brown, R., Gray, R. H., and Bernstein, I. A. (1985) Differentiation 28, 268.

45. Watt, F. M., and Green, H. (1982) Nature (London) 295, 434.

46. Kim, H. J., and Bernstein, I. A. (1984) J. Cell Biol. 99, $314 \mathrm{a}$.

47. Lichti, U., Ben, T., and Yuspa, S. H. (1985) J. Biol. Chem. 260, 1422.

48. Buxman, M. and Wuepper, K. D. (1975) J. Invest. Dermatol. 65, 107.

49. Ku, W. W. (1987) Doctoral thesis, The University of Michigan.

Received September 7, 1987 